Schram, M.T., Waal, M.W.M. de, Craen, A.J.M. de, Deeg, D.J.H., Schellevis, F.G. Multimorbiditeit: de nieuwe epidemie. TSG: Tijdschrift voor Gezondheidswetenschappen: 2008, 86(1), 23-25

\begin{tabular}{|l|l|}
\hline $\begin{array}{l}\text { Postprint } \\
\text { Version }\end{array}$ & 1.0 \\
\hline Journal website & $\begin{array}{c}\text { http://vb23.bsl.nl/frontend/index.asp?custom_product_id=1388- } \\
\text { 7491\&product_id=\{68B1EBF1-7393-458F-BF75-BDB5E9A3DAE9 }\}\end{array}$ \\
\hline Pubmed link & \\
\hline DOI & \\
\hline
\end{tabular}

This is a NIVEL certified Post Print, more info at http://www.nivel.eu

\title{
Multimorbiditeit: de nieuwe epidemie
}

\author{
Miranda T. SCHRAM, MARgot W.M. DE WAAL, ANTON J.M., DORLY J.H. DEEG, \\ FRANCOIS G. SCHELLEVIS
}

De ziektelast van de wereldbevolking neemt toe door de veroudering van populaties. In Westerse landen neemt vooral de prevalentie van chronische aandoeningen toe. Dit leidt ook tot een stijgende prevalentie van multimorbiditeit (het samen voorkomen van meer dan één chronische ziekte in een persoon).

De stijgende prevalentie van multimorbiditeit heeft belangrijke consequenties voor de gezondheidszorg omdat mensen met chronische aandoeningen langdurig zorg nodig hebben. Daarnaast vraagt multimorbiditeit een ander soort patiëntenzorg dan de zorg voor patiënten met geïsoleerde chronische aandoeningen. Ondanks de grote impact die multimorbiditeit heeft op de medische zorg is er slechts beperkt onderzoek naar gedaan. 1 Gedeeltelijk wordt dit veroorzaakt door methodologische problemen die schattingen van het voorkomen multimorbiditeit bemoeilijken. $\underline{2}$

Wij onderzochten de omvang van multimorbiditeit bij ouderen in Nederland. We bepaalden de prevalentie van multimorbiditeit in verschillende settings: de algemene bevolking (met gebruik van gegevens uit twee bevolkingsonderzoeken), de huisartssetting (aan de hand van twee huisartsenregistraties) en het verpleeghuis (aan de hand van een verpleeghuisregistratie).

\section{Multimorbiditeit}

Multimorbiditeit werd gedefinieerd als de aanwezigheid van minimaal twee chronische aandoeningen bij één persoon. Een aandoening werd als chronisch beschouwd bij een duur van minimaal 12 maanden en aanwezigheid van één of twee van de onderstaande criteria: (a) de aandoening zorgt voor beperkingen in zelfzorg, onafhankelijk wonen en sociale interactie; (b) de aandoening resulteert in voortdurende interventie met medicijnen, zorg of speciale benodigdheden. $\underline{3}$ Voor het bepalen van chronische aandoeningen werd gebruikt gemaakt van de Chronic Condition Indicator List ontwikkeld door Hwang et al. $\underline{3}$ Hiervoor werden 578 3digit ICD-9 CM codes beoordeeld door een panel van vijf internisten, die gezamenlijk 185 van deze aandoeningen als chronisch classificeerden. De lijst bevat veel voorkomende maar ook minder vaak voorkomende aandoeningen. Dit betekent dat niet alle 185 aandoeningen zijn geregistreerd in de gebruikte gegevensbronnen. 
Schram, M.T., Waal, M.W.M. de, Craen, A.J.M. de, Deeg, D.J.H., Schellevis, F.G. Multimorbiditeit: de nieuwe epidemie. TSG: Tijdschrift voor Gezondheidswetenschappen: 2008, 86(1), 23-25

\section{ONDERZOEK}

Tabel 1 geeft een overzicht van de kenmerken van de gebruikte gegevensbronnen. Om de prevalentie van multimorbiditeit te bepalen hebben we gebruik gemaakt van de meest recente gegevens van mensen van 55 jaar en ouder van twee bevolkingsonderzoeken (de Longitudinal Aging Study Amsterdam 4 en de Leiden 85-plus studie (85 jarigen) $\underline{5}$ ), twee huisartsen registraties (de Continue Morbiditeits Registratie Nijmegen (CMR Nijmegen) $\underline{6}$ en het Registratie Netwerk Universitaire Huisartspraktijken Leiden en omstreken (RNUH-LEO) $\underline{7}$ en een verpleeghuisregistratie (VU Medisch Centrum Resident Assessment Instrument database (RAI)). 8 Details over onderzoeksopzet en de chronische ziekten die zijn betrokken in de analyses kunnen bij de auteurs worden verkregen.

\section{[TABLE 1]}

\section{RESULTATEN}

Multimorbiditeit varieerde tussen de 56 en $72 \%$ in de algemene bevolking en de huisartsregistraties. Daarnaast blijkt er bij 82\%van de verpleeghuisbewoners sprake van multimorbiditeit. Er was een sterke relatie tussen multimorbiditeit en leeftijd; de prevalentie steeg van $39 \%$ tot $53 \%$ op de leeftijd van 55 tot 64 jaar, tot $83 \%$ tot $95 \%$ bij mensen van 85 jaar en ouder. De relatie tussen multimorbiditeit en leeftijd wordt geïllustreerd in figuur 1 . Voor deze figuur zijn alleen de gegevensbronnen met de grootste leeftijdsrange (55 tot 95 jaar) gebruikt. Daarnaast valt op dat het aantal chronische ziekten per persoon verschuift met de leeftijd. In LASA heeft bijvoorbeeld in de leeftijdsgroep 55 tot 64 jaar 29\% geen, 32\% een, 21\% twee en $10 \%$ drie chronische ziekten. Op 75 tot 84 jarige leeftijd is dit verschoven naar $6 \%$ met geen, $22 \%$ met een, $25 \%$ met twee en $25 \%$ met drie chronische ziekten. In CMR Nijmegen en RNUH-LEO vinden soortgelijke verschuivingen plaats.

In de verpleeghuispopulatie hangt multimorbiditeit niet samen met leeftijd. De prevalentie van multimorbiditeit tussen mannen en vrouwen bleek niet consistent te verschillen.

\section{[FIGURE 1]}

\section{CONCLUSIE}

Multimorbiditeit komt heel veel voor onder ouderen in Nederland. Bij meer dan 50\% van de mensen van 55 jaar en ouder is sprake van multimorbiditeit. Daarmee is multimorbiditeit eerder regel dan uitzondering. Multimorbiditeit blijkt sterk samen te hangen met leeftijd. Onder personen met een hoge zorgbehoefte, zoals verpleeghuisbewoners, is multimorbiditeit echter niet gerelateerd aan leeftijd. Multimorbiditeit blijkt niet te verschillen tussen mannen en vrouwen.

Eerdere onderzoeken hebben laten zien dat multimorbiditeit is gerelateerd aan een slechtere kwaliteit van leven, meer zorggebruik, hogere medische kosten en een 
Schram, M.T., Waal, M.W.M. de, Craen, A.J.M. de, Deeg, D.J.H., Schellevis, F.G. Multimorbiditeit: de nieuwe epidemie. TSG: Tijdschrift voor Gezondheidswetenschappen: 2008, 86(1), 23-25

verhoogde kans op sterfte. 9-11 Daarnaast brengt multimorbiditeit polyfarmacie met zich mee met een verhoogd risico op interacties en bijwerkingen. Problemen met het gebruik van meerdere geneesmiddelen zijn jaarlijks verantwoordelijk voor een aanzienlijk aantal ziekenhuisopnamen. De hoge prevalentie van multimorbiditeit illustreert de noodzaak om meer aandacht te besteden aan multimorbiditeit en de consequenties ervan voor de gezondheidszorg.

De resultaten van dit onderzoek roepen ook vragen op over de manier waarop de Nederlandse gezondheidszorg is georganiseerd. Multimorbiditeit wordt vaak over het hoofd gezien in de huidige ziekte-georiënteerde organisatie van de zorg, omdat hierin ziektespecifieke diagnose- en behandelingsstrategieën centraal staan. 12 Ook worden 'orgaanspecialisten' op dit moment niet opgeleid om verschillende aandoeningen in meerdere orgaansystemen te herkennen en te behandelen. Daarnaast is het gebruikelijk dat patiënten met multimorbiditeit worden uitgesloten van deelname aan klinisch onderzoek, omdat zij de interpretatie van de onderzoeksresultaten kunnen bemoeilijken. Dit laatste belemmert de ontwikkeling van een evidence-base voor de behandeling van patiënten met multimorbiditeit. Een goed gecoördineerde, patientgeörienteerde benadering van de zorg ('zorg op maat') lijkt geschikter voor ouderen met multimorbiditeit.

De resultaten van dit onderzoek laten een lagere prevalentie van multimorbiditeit in de algemene bevolking zien ten opzichte van de huisartsenregistraties (Figuur 1). Dit wordt vermoedelijk veroorzaakt door het lagere aantal aandoeningen dat binnen de bevolkingsonderzoeken wordt geregistreerd. De hogere prevalentie van multimorbiditeit in de CMR Nijmegen ten opzichte van de RNUH-LEO wordt waarschijnlijk veroorzaakt doordat de CMR Nijmegen gegevens van de tien voorgaande jaren heeft gebruikt om de prevalentie van multimorbiditeit te bepalen, terwijl de RNUH-LEO gegevens van vijf voorafgaande jaren heeft gebruikt. Schram et al $\underline{13}$ beschrijft het type aandoeningen waaruit multimorbiditeit in verschillende settings bestaat.

Samenvattend, blijkt de prevalentie van multimorbiditeit in de oudere Nederlandse bevolking opmerkelijk hoog te zijn. Daarnaast is deze sterk gerelateerd aan leeftijd, waardoor de absolute aantallen patiënten in de komende jaren verder zullen toenemen door de vergrijzing van de Nederlandse bevolking. Tot op dit moment heeft multimorbiditeit onvoldoende aandacht in de Nederlandse gezondheidszorg. Zowel gezondheidszorg professionals als beleidsmakers zouden de zorg voor mensen met multimorbiditeit hoog op de prioriteitenlijst moeten zetten.

\section{VERANTWOORDING}

Dit onderzoek is uitgevoerd in opdracht van en werd gefinancierd door de Gezondheidsraad van het ministerie van Volksgezondheid, Welzijn en Sport. We willen de volgende collega's die bij dit onderzoek betrokken waren bedanken voor hun bijdrage: D. Frijters, EMGO instituut, VU Medisch Centrum, Amsterdam en E.H. van de Lisdonk, afdeling Huisartsgeneeskunde, Radboud Universiteit Nijmegen, Nijmegen. 
Schram, M.T., Waal, M.W.M. de, Craen, A.J.M. de, Deeg, D.J.H., Schellevis, F.G. Multimorbiditeit: de nieuwe epidemie. TSG: Tijdschrift voor Gezondheidswetenschappen: 2008, 86(1), 23-25

* EMGO Instituut, VU Medisch Centrum, Amsterdam

** Afdeling Huisartsgeneeskunde, Leids Universitair Medisch Centrum, Leiden

*** Afdeling Ouderengeneeskunde, Leids Universitair Medisch Centrum, Leiden

**** NIVEL, Utrecht

Literatuur

1. Fortin M, Lapointe L, Hudon C, Vanasse A. Multimorbidity is common to family practice: is it commonly researched? Can Fam Physician 2005;51:244-245.

2. Akker M van den, Buntinx F, Roos S, Knottnerus JA. Problems in determining occurrence rates of multimorbidity. J Clin Epidemiol 2001;54:675-679.

3. Hwang $W$, Weller $W$, Ireys $H$, Anderson $G$. Out-of-pocket medical spending for care of chronic conditions. Health Aff (Millwood ) 2001;20:267-278.

Deeg DJ, Tilburg T van, Smit JH, Leeuw ED de. Attrition in the Longitudinal Aging

4. Study Amsterdam. The effect of differential inclusion in side studies. J Clin Epidemiol 2002;55:319-328.

Wiel AB der, Exel E van, Craen AJ de et al. A high response is not essential to prevent

5. selection bias: results from the Leiden 85-plus study. J Clin Epidemiol 2002;55:11191125.

6. Weel C van. Longitudinal research and data collection in primary care. Ann Fam Med 2005;3 Suppl 1:S46-S51.

7. Waal M de. RNUH-LEO basisrapport VI, Department of General Practice and Nursing Home Medicine. Leiden University Medical Centre. 1994.

Achterberg W, Pot AM, Campen C van, Ribbe M. Het Resident Assessment Instrument

8. (RAI). Een overzicht van internationaal onderzoek naar de psychometrische kwaliteiten en effecten van implementatie in verpleeghuizen. Tijdschr Gerontol Geriatr 1999;30:264-270.

9. Gijsen R, Hoeymans N, Schellevis FG et al. Causes and consequences of comorbidity: a review. J Clin Epidemiol 2001;54:661-674.

10. Fortin M, Lapointe L, Hudon C et al. Multimorbidity and quality of life in primary care: a systematic review. Health Qual Life Outcomes 2004;2:51.

11. Byles JE, D'Este C, Parkinson L, O'Connell R, Treloar C. Single index of

11. multimorbidity did not predict multiple outcomes. J Clin Epidemiol 2005;58:997-1005.

12. Weel $C$ van, Schellevis FG. Comorbidity and guidelines: conflicting interests. Lancet 12. 2006;367:550-551.

Schram MT, Frijters D, Lisdonk EH van de et al. Setting and registry characteristics

13. influenced the prevalence and nature of multimorbidity in the elderly. J Clin Epidemiol (in press). 
Tables

Tabel 1. Kenmerken van de gebruikte databronnen

Bevolkingsonderzoeken

Huisartsenregistraties

Verpleeghuisregistr

\begin{tabular}{|c|c|c|c|c|c|}
\hline & LASA & $\begin{array}{l}\text { Leiden 85+ } \\
\text { Studie }\end{array}$ & $\begin{array}{c}\text { CMR } \\
\text { Nijmegen }\end{array}$ & RNUH-LEO & \\
\hline Setting & $\begin{array}{l}\text { Algemene } \\
\text { bevolking }\end{array}$ & $\begin{array}{l}\text { Algemene } \\
\text { bevolking }\end{array}$ & Huisarts & Huisarts & Verple \\
\hline Steekproefgrootte & 2.463 & 599 & 2.895 & 5.610 & 1.274 \\
\hline Vrouwen (\%) & 56 & 67 & 53 & 52 & 70 \\
\hline Leeftijdsrange & $55-94$ & 85 & 55 en ouder & 55 en ouder & 55 en o \\
\hline $\begin{array}{l}\text { Werving } \\
\text { Actieve } \\
\text { opsporing van } \\
\text { aandoeningen }\end{array}$ & Uitgenodigd & Uitgenodigd & $\begin{array}{l}\text { Geregistreerd } \\
\text { bij huisarts }\end{array}$ & $\begin{array}{l}\text { Geregistreerd bij } \\
\text { huisarts }\end{array}$ & $\begin{array}{l}\text { Bewone } \\
\text { verpleegh }\end{array}$ \\
\hline $\begin{array}{l}\text { Meetperiode } \\
\text { Aantal } \\
\text { geregistreerde } \\
\text { ziekten }\end{array}$ & 2002 & 1997 & 2005 & 2006 & 2005 \\
\hline $\begin{array}{l}\text { Diagnostische } \\
\text { validiteit }\end{array}$ & $\begin{array}{l}\text { - } \\
\text { Zelfrapportage } \\
\text { - Huisarts } \\
\text { gegevens }\end{array}$ & $\begin{array}{l}\text { - } \\
\text { Huisartsgegevens } \\
\text { - Medische } \\
\text { gegevens } \\
\text { - } \\
\text { Apotheekgegevens } \\
\text { - Lichamelijk } \\
\text { onderzoek }\end{array}$ & - Huisartsdiagnose & - Huisartsdiagnose & $\begin{array}{l}\text { - } \\
\text { Verpleegk } \\
\text { diagnose } \\
\text { RAI } \\
\text { vragenlij }\end{array}$ \\
\hline
\end{tabular}

LASA, Longitudinal Aging Study Amsterdam, CMR Nijmegen, Continue Morbiditeits Registratie Nijmegen, RNUH-LEO, Registratie Netwerk Universitaire Huisartspraktijken Leiden en omstreken, RAI, VU Medisch Centrum Resident Assessment Instrument database 
Schram, M.T., Waal, M.W.M. de, Craen, A.J.M. de, Deeg, D.J.H., Schellevis, F.G. Multimorbiditeit: de nieuwe epidemie. TSG: Tijdschrift voor Gezondheidswetenschappen: 2008, 86(1), 23-25

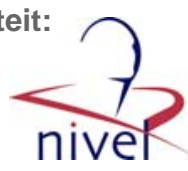

Figures

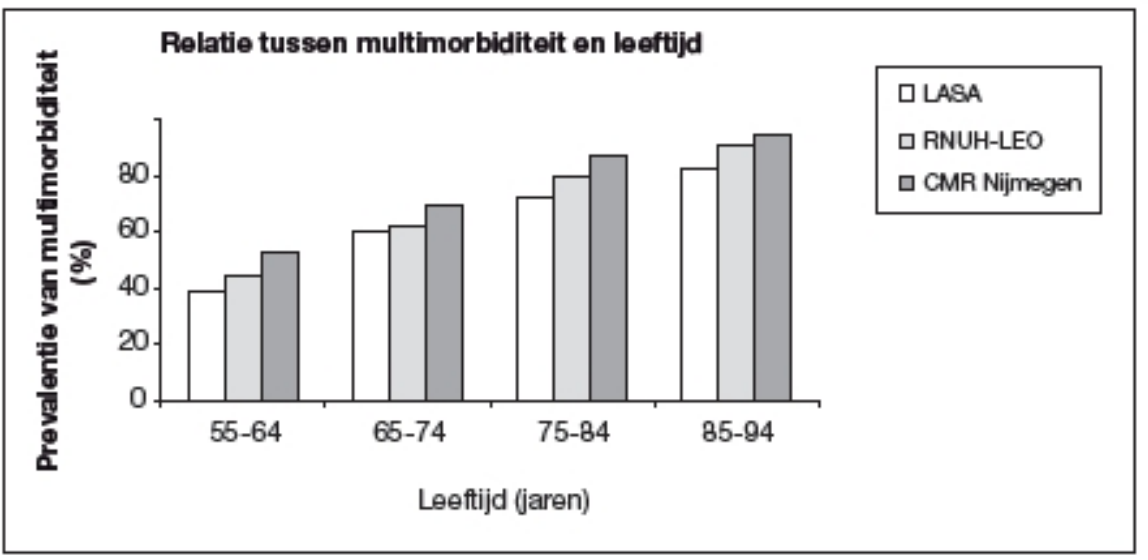

Figuur 1. De relatie tussen multimorbiditeit en leeftijd. 